\author{
Andrzej Stoiński \\ University of Warmia and Mazury in Olsztyn \\ Faculty of Humanities \\ Institute of Philosophy \\ e-mail: andrzej.stoinski@gmail.com
}

\title{
Exploitation in the face of justice*
}

\begin{abstract}
The paper refers to selected issues of exploitation in the face of justice. The analysis is based on the definitions of exploitation contained in the Polish Penal and Civil Codes. The main goal is the identification of the necessary and sufficient conditions for the recognition of exploitation as being unjust. A supplementary question will refer to a specific type of justice which should be considered in this case. In this respect, we should consider retributive, distributive and social justice. Another important factor in this regard is the accepted theory of value. In the presented considerations, we will focus on the labour theory of value. The principal issue can be expressed by the questions whether exploitation is ipso facto unjust and how the phenomena of exploitation and justice are related to each other.
\end{abstract}

Keywords: ethics, justice, exploitation

JEL Classification: B51, B53, Z13

Since the matter under discussion is extremely extensive and encompasses many areas of reflection, the deliberations on the issues related to justice or injustice of exploitation will be significantly limited. We will focus in this respect on the most important aspects of the subject in our opinion. Above all, we will attempt to clarify what kind of situation constitutes exploitation.

\footnotetext{
* The article is an updated version of the paper published in Polish in the Annales. Ethics in Economic Life, 17(3), 31-42.
} 


\section{Exploitation}

We start our reflection by defining what exploitation is in the most general sense. We will refer in this respect to the provisions contained in legal acts. Exploitation in the light of the Civil Code (Article 388 of the Polish Civil Code) is defined as a situation in which one of the parties, taking advantage of an unfavourable position of the other party, accepts or reserves for itself a benefit from the other party. ${ }^{1}$ The substantive and procedural conditions of exploitation are as follows (Polish Civil Code, Article 388, § 1):

(1) there is a gross disproportion of benefits gained,

(2) one of the parties is in an unfavourable position (out of necessity or due to its infirmity or inexperience), and

(3) the other party takes advantage of this situation, while

(4) it reserves for itself (or a third party) or accepts the benefit of the party which is in the unfavourable position.

Exploitation has been similarly defined in the Penal Code (Article 304), which states that:

Whoever exploits a coercive situation of another natural person, juridical person or organisational entity without a legal personality by concluding a contract with such person or entity, imposing an obligation of making a performance incommensurate with the reciprocal performance, is subject to the penalty of deprivation of liberty for up to 3 years.

Considering the relevant articles, exploitation is a relationship between two parties. All human interactions considered in terms of their profitability can be divided into three types:

(1) profitable interactions from which both parties benefit (or one benefits and the other does not suffer any loss),

(2) one-sidedly profitable interactions in which one party gains, while the other loses (in the proportional terms, it is called the zero-sum game),

(3) mutually unprofitable interactions in which both parties participating in the interaction suffer a loss (or one loses and the other does not benefit).

From the perspective of the above-presented division, exploitation cannot be a type of interaction described in point (3). We are therefore left with considering the possibility of (1) and (2). Hence, exploitation is a situation in which both parties gain, however, the profitability of one or both parties is incommensurate with the contribution, or one of the parties' gains, while the other does not benefit or even loses. The content of the first substantive and procedural premise on the disproportion of benefits clearly suggests that benefits gained are mutual but disproportionate.

\footnotetext{
${ }^{1}$ For comments on the institution regulated by Article 388 of the Polish Civil Code, i.e. the definition of exploitation, cf. http://www.openlaw.com.pl/wikka.php?wakka=Wyzysk.
} 


\section{Justice}

The conditions of just action will be an issue requiring explanation in the light of the premises of exploitation. However, to present them, we should first clarify what kind of justice we should consider in this case, or what kind of justice should be used in the evaluation of exploitation. We have several candidates to choose from. We can consider distributive justice, the so-called social justice, as well as retributive justice, and specifically its variations: commutative and punitive justice (or performing the same function as punitive justice - restorative justice). Among the presented possibilities, we should first of all rule out distributive justice, since in the classification of the varieties of justice it has already been identified as the type of justice which refers to the sharing of public goods between community members (Aristotle, 1996, pp. 172-174). Social justice is usually understood as complementary to the formula of distributive justice- "to each according to his justified needs" (Ziembiński, 1996, p. 25). For this reason, it should also not be associated with the phenomenon of exploitation. ${ }^{2}$ Among the forms of retributive justice, punitive and restorative ones apply to the circumstances of compensating for losses that have occurred as a result of violence or fraud (Aristotle, 1818, p. 176). Thus, this type of justice cannot be applied when such a fact has not yet taken place. Ultimately, therefore, only commutative justice remains.

After determining which of the varieties of justice refers to the phenomenon of exploitation, let us examine the conditions of a just and unjust act. They relate to the subject-related and object-related circumstances of the analysed relationship. We will start by considering the situation of entities taking part in mutual interactions. They may be entities with an equal or unequal legal status. The existence of a just relation will be determined by the equality of the parties in relation to the objects of exchange. Equality will be understood in this way that regardless of the economic, social or other situation of the parties, they are entitled to the same rights. What we mean here is, first and foremost, a ban on the violation of negative freedom of the other party. If, for example, one of the parties is not allowed to violate the bodily integrity, property or another good of the other party, then the first party is also entitled to the same right. Equality of the parties, obviously, does not necessarily imply the same level of some economic, intellectual, moral or other types of status of the involved entities. In this regard, each of the parties holds its own special and distinctive position. The dissimilarity of their condition in any of the many possible areas is, in fact, characteristic of all entities in relation to one another, which, incidentally, is not synonymous with their inequality.

In the object-related aspect of the interaction, we will refer to what is the object of performance provided by both parties. It is a good or at least something that is considered as a good by both parties. The necessary and at the same time sufficient condition for the exchange to be just, in this case, is the voluntary aspect of

\footnotetext{
${ }^{2}$ In some interpretations, actions inspired by the idea of social justice can, however, be assessed as generating exploitation through the state.
} 
the exchange, supplemented by the requirement of the lack of coercion/deception or taking advantage of infirmity in the process of deciding on the involvement in the exchange. Injustice appearing in such an interaction will in our opinion be related to the failure to meet one of the premises, i.e. the necessary condition for the recognition of the occurrence of an unjust exchange will be: (1) the parties' inequality, and/or (2) the involuntary nature of benefit from the exchange.

\section{Injustice of exploitation}

As the preliminary clarifications have revealed the general outline of what exploitation is and what actions should qualify as unjust, we can now examine more closely the premises of exploitation in the light of commutative justice based on the specific characteristics made. Generally, they can be divided into those that relate to the disproportion of benefits and those that refer to the position of the parties.

The issue of disproportions is closely associated with the issue of proper assessment of this inequality. This is particularly related to the adopted evaluation criteria. The subject-related criterion determines who makes the evaluation. The object-related criterion refers to the point of view from which the assessment is made, or what determinants are relevant in this case. As to who makes the evaluation, we can assume that it is performed by some external entity in relation to the parties involved in the relationship or that it is made by the parties themselves. If the proportionality assessment is performed by an external entity, the opinion in this matter will depend on the measure adopted by the evaluator. A measure of an objective nature may be, for example, a reference to the absolute value of the provided goods, or it may also be a reference to other previous cases or adopted norms. It seems that depending on the resolution of the subject-related matter, we should obtain different solutions in the object-related field. In the case when the assessment is carried out by the parties themselves, we can assume that they will primarily refer not to the objective, but the subjective value attributed to the offered good. However, regardless of which method of evaluation we would consider optimal, the wording in both Codes refers to the external evaluation in relation to both parties of the exchange. From this perspective, it is worth noting that the Code premises of exploitation differ from the premises designated for unjust actions in the light of commutative justice. In the case of this type of justice, neither the disproportion of benefits nor the position of the parties determines the recognition of the occurrence or non-occurrence of a situation of injustice.

In the case of voluntary exchanges (assuming no coercion/deception or taking advantage of infirmity and equality of the involved parties), it is assumed that whatever the contractual relationship between the parties, both will recognise that they have received what they are entitled to. This is enough to consider the mutual relationship of the parties in the light of commutative justice as just. Moreover, the mere fact of a voluntary exchange should also rightly be considered a sufficient 
premise to conclude that both parties recognise that they have provided a benefit of a value lower than that which they have received ${ }^{3}$, or that they assume that they have received benefits of at least equal value. In the light of the above, it is difficult to write about disproportions of benefits. This kind of determination is possible from the external perspective of the parties involved, i.e., when the assessment of the value of the benefit comes from other entities than the parties involved. Negative assessment in the context of commutative justice is also possible in the case of the violation of the condition of equality of entities participating in a given interaction. It seems, therefore, that it should be recognised that the very premise of the disproportion of benefits without the additional condition of parties' inequality cannot yet determine the occurrence of the injustice of exploitation.

Another group of premises of exploitation concerns the unfavourable position of the party. By analysing this point, we will start with a truism. The two entities entering a relationship are hardly ever on equal footing. One party may be in a slightly more advantageous position than the other. An 'unfavourable' position is a relative term in the sense that it is always in comparison with the position of the other entity. Someone worth a million is in a more disadvantageous position than a person who has ten million. We should also not ignore in this regard the fact that each position affects the perception of the value of the good possessed (benefit provided) and the evaluation of other, not yet possessed goods (benefits offered). An unfavourable position of a person means that the value of the good (potential benefit) at his or her disposal decreases in relation to the value of the exchangeable goods (benefits) in the possession of people who are in a better position. As one can see, the value of benefits offered is always associated with a certain context in which their provision occurs. Therefore, we will refer to another truism here, noting that someone in a coercive position is always in a worse situation than the person who is not in such a position. It follows that the value of the benefits offered by the first party decreases in relation to the value of the benefits offered by the latter one ceteris paribus. If, in this situation, there is a voluntary exchange (in which, it is worth emphasising, one of the parties is always in a more coercive situation than the other) ${ }^{4}$, and there is no coercion/deception or taking advantage of infirmity in the exchange, it is difficult to classify such an

\footnotetext{
${ }^{3}$ Referring to the value of the benefit, we will mean both the value of the object of exchange itself, as well as its contextual value, i.e. all the benefits that the party subjectively perceives, and which are associated (also not directly) with the exchange relation. Such a contextual value can be, for example, the value that the exchanger ascribes to the fact that the other party will feel the pleasure of the exchange itself or the belief that it is making a "good deal". As an example of the contextual value, we can also recognise the satisfaction derived by offering a good of a higher value in exchange for one of a lower value, thus helping someone worse off, performing a good deed, distributing wealth, etc. In any case, we acknowledge that people enter exchange to receive a higher value (also contextual) in exchange for a lower value. This contextual value can be justified, as Murray N. Rothbard does providing an observation of the Austrian School that "people, even in business, act more to maximise their "psychic « rather than monetary profit, and that such a psychic profit may include all sorts of values, none of which is more or less arbitrary than another" $(2015$, p. 220$)$.

4 “A person's choice among differing degrees of unpalatable alternatives is not rendered non-voluntary by the fact that others voluntarily chose and acted within their rights in a way that did not provide him with a more palatable alternative" (Nozick, 1974, p. 263-264).
} 
exchange as unjust. If we do not agree to recognise it as just, then we should at least classify it as not unjust. ${ }^{5}$ Thus, this condition of exploitation does not enforce the recognition of injustice, despite the coercive position of one of the parties. This will happen only if the coercive position of the party is accompanied by the condition of involuntary exchange (concluded under coercion/deception or taking advantage of infirmity ${ }^{6}$ ). To sum up, we should add an important caveat. The observations regarding the value of benefits offered presented above do not in any way override another, this time a moral aspect of the whole issue, i.e. the nature of mutual relations, for which Kant's categorical imperative seems to be one of the decisive determinants. ${ }^{7}$

Returning to the subject of the violation of the rules of justice because of exploitation, let us note that the condition that is necessary for the recognition of the occurrence of the latter is the receipt of a disproportionately low compensation for benefit provision. We could add here the case of unilateral benefit provision, but this kind of benefit, which is not reciprocal, does not constitute an exchange, and if it happens voluntarily, then we should classify it as a kind of gift. If it were involuntary, it would have to be considered as a form of theft (robbery). We have pointed out earlier that if the conditions of voluntariness and equal rights are met, the exchange does not qualify as unjust. Starting from this point of view, an unjust benefit may be a result of the occurrence of either or both two situations: (1) a reservation in a specific interaction of a different status for the benefit recipient than for the benefit provider (inequality), and/or (2) the violation of voluntariness of benefit provision (involuntariness). It seems that in any other case the exchange of benefits is a sort of contract. This, to be valid, requires equal freedom (a lack of coercion/deception or taking advantage of infirmity) ${ }^{8}$ of the parties involved in the scope relevant to this contract. Let us note that taking advantage of infirmity meets one of the conditions for the occurrence of exploitation. In any other case, it should be assumed that there was a voluntary agreement to accept the benefit offered born from the conviction (it can only be temporary, variously motivated, etc.) that the benefit received in exchange (regardless of its specific characteristics) is more favourable than what is offered.

\footnotetext{
${ }^{5}$ That is, one that is not subject to the "just-unjust" classification.

${ }^{6}$ Infirmity, which is worth noting, also brings about inequality of individuals, which is expressed in the inability to consider significant conditions important in estimating the value of benefits.

${ }^{7}$ Particularly the one known as the practical imperative in the wording: "Act in such a way that you treat humanity, whether in your own person or in the person of any other, never merely as a means to an end, but always at the same time as an end" (Kant, 1981, p. 37).

${ }^{8}$ The scope of the presented conditions of validity should also encompass among the above-presented ones, a lack of coercion threat, immaturity, incapacity of understanding the consequences resulting from the contract, ill will or non-disclosure of important information.
} 


\section{Other attempts to approach the issue}

If confronting the premises of exploitation with the conditions of fair exchange allows us to conclude that in the light of this type of justice the determination of the injustice of exploitation based on the premises considered is unfounded, does it mean that this issue is ultimately clarified? It does not seem so. This issue can also be considered on the basis of other concepts of justice than commutative and other methods of assessment than the subjective evaluation of benefits by the parties involved in the exchange. For a change, one can try to rely on the process of evaluation on objective grounds, and as proposed by Marx, one may rely on the principles of distributive justice - a view on the injustice of exploitation that refers to the labour concept of values. ${ }^{9}$ We may add that the view of exchange based on exploitation is also found in considerations of the thinker referring to the objective theory of value, i.e. Aristotle (2005, p. 28). "Also" because in another place, the same philosopher states that "who gives what is his own, is not injured [...]".

The labour proposition is a mutation of the objective value concept. According to the latter, the value of goods is measurable and, in principle, independent of subjective convictions. Marx's theory concretises the above-presented assumption, linking it to the amount of labour contained in each product which is the object of exchange. By following this concept, Marx sees the source of exploitation in unequal access to the means of production. ${ }^{11}$ Workers, deprived of this possibility, are forced to sell their labour to capitalists. ${ }^{12}$ Their impairment in the possession of means of production puts workers in a disadvantageous position, which fills one of the premises of exploitation. The other type of premises referring to the disproportion of benefits is in turn conveyed in the belief that the rate of surplusvalue generated in the production process "is an exact expression for the degree of exploitation of labour-power by capital, or the labourer by the capitalist." (Marx, 2007, p. 241). Such a statement seems to suggest unequivocally that the entire surplus-value generated in the production process is collected by the capitalist, which should mean that the capitalist receives from the worker a disproportionately high benefit. If, however, we accept such a point of view and agree that

\footnotetext{
${ }^{9}$ This concept is also referred to as the theory of value based on labour (Landreth \& Colander, 2005, pp. 102-111; Stephenson, 1972).

${ }^{10}$ Aristotle (1818, p. 183-184) illustrates this with a quote from ancient classics:

"But he who gives what is his own, as Homer says Glaucus gave to Diomed,

For Diomed's brass arms of mean device,

For which nine oxen paid, a vulgar price,

He gave his own of gold divinely wrought,

A hundred beeves the shining purchase bought.

Is not injured [...]."

${ }^{11}$ Robert Nozick believes that in this kind of approach to this issue, only one premise is a decisive qualification, as in the Marxist concept, "it is this crucial fact of non-access to the means of production that underlies exploitation [...]" (1974, p. 254).

${ }^{12}$ Nozick (1974, p. 253-262) points out that today, as in the past, in the case of possession of cash (savings, access to credit, etc.), the charge of exploitation seems pointless. It seems that mainly the ability and willingness (or unwillingness) to take risks determine who becomes the capitalist (in fact, the entrepreneur) and who does not.
} 
exploitation should be measured by the profit of the capitalist-manufacturer, then it will turn out that any activity aimed at making a profit using mercenary labour can be classified as the realisation of wrongful exploitation. If the activities undertaken in the market are mostly profit-oriented then all ventures undertaken with the participation of hired employees are some form of an exploitation. Avoiding such a conclusion would be possible only under conditions in which the entire surplus-value would be distributed among hired employees. The capitalist should not be left with anything, as such an assigned surplus-value will be a measure of exploitation. Therefore, capitalist exploitation would disappear only without the surplus-value assigned to the manufacturer. The natural consequence of such thinking is the Marxist requirement of socialising the means of production where the surplus-value is shared among workers without the participation of the capitalist owner. Under such conditions, the premise of an unfavourable position of the party would also cease to exist.

The disparity between the situation of the capitalist and the worker is explained by Marx based on the labour concept of values. Eugen von Böhm-Bawerk notes, however, that this theory has many significant flaws that result in its final uselessness. First, the author emphasises that:

experience shows that the exchange value of goods stands in proportion to that amount of labour which their production costs only in the case of one class of goods, and even then, only approximately. (Böhm-Bawerk, 1957, p. 269)

Other relevant factors affecting the evaluation include, for example, rarity, quality, storage time, demand/supply ratio, fashion, and the reputation of the manufacturer.

Marx's hypothesis also contains another weakness, i.e., an employeeemployer relationship as a transaction for the exchange of services (in a broader sense, it includes not only labour in the strict sense, but also, for example, time, skills, knowledge, reputation, etc.) in return for remuneration. It is an exchange of goods. The labour theory seems to ignore the fact that a voluntary exchange is a positive-sum relationship while Marx treats it as a zero-sum interaction. The characteristic of this type of interaction is that if one party is to gain, the other must lose. Böhm-Bawerk (2007, p. 68) emphasises that Marx perceives exchange as a form of an equation. In reality, however, it is a relationship based on a subjective conviction about the benefits derived from such an exchange. For it to be just, the parties do not have to have equal opportunities, but they must have equal rights. In such circumstances, the exchange takes place based on the conviction of both parties that the good of a lesser value is exchanged for another good of a greater value. Therefore, it is (at least considering subjective convictions of both parties) a positive-sum relationship. It cannot be such an interaction only in the case when the determination made by the parties involved is rejected and replaced by the evaluation which is independent of the assessment of both parties. Marx uses exactly such a procedure, as he conducts the estimation from the point of view of the labour factor as an essential element of product valuation. However, as Böhm-Bawerk, quoted by us earlier, points out, labour does not have to be the 
only or even the main measure of value. Moreover, even if we accept this way of reasoning, we will encounter complications that are difficult to overcome. Every type of work done is either the original transformation of what is found in nature or a modification of the effects of previously undertaken efforts. In the first case, its value is relative to the utility it brings to someone, and it is estimated from this perspective. Such initial estimation is based on subjective criteria. In the latter case, the labour value consists of previous activities which are made up of earlier ones, etc. In this regression, we finally come back to the original transformation the value of which is given because of the first buyer' subjective assessment. Thus, the value of labour is still based, even if we do not accept the view that all the time, on some initial biased evaluation. This, in turn, seems to undermine Marx's claim of labour as an objective measure of value. The consequences of this are pointed out by Nozick $(1974$, p. 253$)$, who states that "with the crumbling of the labour theory of value, the underpinning of its particular theory of exploitation dissolves."

Perceiving the production of goods as a zero-sum interaction can also be criticised from another point of view. Market production is a dynamic process in the sense that it increases the stock of goods. It happens as a result of creative activities of an organisational and intellectual nature and labour input, which means is what previously did not exist, i.e. this surplus-value is shared between the entrepreneur and the employees (more on the subject in de Soto, 2010, pp. 9-62).

Other objections that can be made with regards to Marx's position refer to ethical arguments. The adoption of an objective concept of value cannot be applied to the situation of voluntary exchange without questioning the subjective autonomy of persons which is confirmed in the valuation process. Independence of the subject, or at least postulating this independence within a given scope, forms the basis of the principle of justice expressed by handing over/holding/receiving what is due. In the case of commutative justice, what is due is what has been freely agreed upon by both parties in the absence of coercion/deception and taking advantage of infirmity. Any other way of deciding what is due in an exchange relationship would be based on a decision imposed by an external factor in relation to the parties involved in the exchange relationship. This would violate the condition of the subjective autonomy of the person and equality and/or voluntariness characterising the direct participants of the exchange. The latter in turn means that such an arbitrary determination would not refer to a situation that can be assessed in the light of commutative justice.

After considering the issue of the objective value of goods that are the objects of exchange, we still must ponder the merits of considering exploitation in the light of a different concept than commutative justice. The natural option will be in this case distributive justice. John Rawls thinks that exploitation is an example of the violation of its specific formula: "to each according to his contribution" (2009, p. 305). The author of $A$ Theory of Justice complements this statement with, as it seems, not entirely clear, declaration that exploitation has little to do with market flaws. Interpreting this remark, it can be assumed that since distributive justice, as we have mentioned, does not refer to the relation of market exchange, but to the 
distribution of goods and burdens within the community, the determination whether the characteristics of some state actions meet the criteria of exploitation cannot be excluded. Even if it was not what Rawls meant, it is hard to resist the impression that "something is the matter".

\section{Exploitation and fair pay}

Another, somewhat more detailed issue related to exploitation is the matter of fair pay. The relationship between these two elements refers to the amount of remuneration received for a specific job. This may have an impact on our considerations in terms of the analogy of the employer's and employee's situation concerning potential exploitation-related claims made by the parties of the exchange. What interests us is the answer to the question of whether there is such a level of pay that can be recognised as exploitation in the employer-employee relationship. And if so, which factors are responsible and to what degree?

When we consider fair remuneration for work, a question arises what should be rewarded in social relations. The often-emerging answer is that effort or talent should be rewarded (cf. Brighouse, 2007, p. 48 et seqq). Sometimes, in this context, also the notion of 'socially useful work' is mentioned. However, this last perspective puts us in a tricky position related to the problem of defining the usefulness of this work. The answer to the question of what kind of work is socially useful and what kind is not, and what sort of work is better than another in this respect, seems to require in principle a reference to some more general ideological solution. In our opinion, it would be wiser to refer in this matter to long-standing views without such an ideological base. They are expressed by the natural conviction that in the field of economic exchange what is rewarded and should be rewarded is what someone is willing to pay for. The adoption of this simple point of reference pushes to the background the question whether the product offered is a result of the ability, effort or time devoted to it. Consequently, anyone who wishes to receive remuneration for the offered good should be guided by these premises. This approach means that considerations regarding fair rewarding of time, effort or talent seem to be pointless. ${ }^{13}$ Despite the declaration of the nature of mutual exchange expressed by us, the remarks made above require some commentary. The fact that we assume that the value of certain goods is subjectively evaluated in the exchange process does not mean that we accept here as true the view of the relative character of values in general, and of moral values.

\footnotetext{
13 The approach underlining the rewarding of talent is commented on by Kazimierz Ajdukiewicz (1960, p. 375): "for what is not the work of a given man, nothing good or bad is due to him unless it is due to everyone. [...] For the talent itself, nothing is due, but for the object that is created by talent."
} 


\section{Conclusions}

Returning to the subject under consideration, we may summarise it by answering the following questions:

(1) Does exploitation determine every remuneration as unfair (within the framework of the concept of commutative justice)? We will also try to reverse this question as:

(2) Does every unfair pay (within the framework of the concept of commutative justice) fall into the category of exploitation?

It has been suggested that the occurrence of substantive and procedural premises of exploitation do not allow for the determination of the occurrence of injustice, therefore, not every remuneration act meeting the criteria of exploitation automatically fulfils the criteria of an unjust action.

What we may call unfair remuneration includes payments that violate the condition of voluntary expression of will in the exchange relationship and payments that do not give what is due. They can give less than is due, or they can more than is due. Both are unfavourable, but one for the payer, the other for the payee. Thus, any unjust action is exploitation either of the payer or the recipient).

Generalising the case of remuneration, and at the same time answering the question posed at the beginning of this text, we can say that not every premise of exploitation determines the actions in the framework of exchange as unjust, but only those in which taking advantage of an infirmity of one of the parties occurs. Each unjust action will at the same time meet the criteria of exploitation. In conclusion, we can say that not all exploitation is unjust (in light of the commutative variant of justice), but any injustice (commutative) concurrently meets the criteria of exploitation.

\section{References}

Ajdukiewicz, K. (1960). O sprawiedliwości. In Język i poznanie (vol. 1). Warszawa: Państwowe Wydawnictwo Naukowe.

Aristotle. (1818). Nicomachean Ethics. In The Rhetoric, Poetic, and Nicomachean Ethics of Aristotle (T. Taylor, Trans.). London: James Black \& Sons.

Aristotle. (1996). Nicomachean Ethics [Etyka nikomachejska] (D. Gromska, Polish trans.). Warszawa: Wydawnictwo Naukowe PWN.

Aristotle. (2005). Politics [Polityka] (L. Piotrowicz, Polish trans.). Wrocław: Ossolineum, DeAgostini.

Böhm-Bawerk, E. (1957). Capital and interest: A critical history of economic theory (W. A. Smart, Trans.). New York: Kelly \& Millan.

Böhm-Bawerk, E. (2007). Karl Marx and the close of his system. Auburn: Ludwig von Mises Institute.

Brighouse, H. (2007). Sprawiedliwość (S. Królak, Trans.). Warszawa: Sic! 
Kant, I. (1981). Grounding for the metaphysics of morals (J. Ellington, Trans.). Indianapolis: Hackett.

Kodeks cywilny, Dz.U. z 1964r. Nr 16, poz. 93 z późn. zm. (Civil Code, Journal of Laws 1964. No. 16, item 93 as amended).

Landreth, H., \& Colander D. C. (2005). Historia myśli ekonomicznej (A. Szeworski, Trans.). Warszawa: Wydawnictwo Naukowe PWN.

Marx, K. (2007). Capital: A critique of political economy (Vol. 1). New York: Cosimo.

Nozick, R. (1974). Anarchy, state, and Utopia. New York: Basic Books.

Rawls, J. (2009). A theory of justice. London: Harvard University Press.

Rothbard, M. N. (2015). The ethics of liberty. New York University Press.

de Soto, J. H. (2010). Teoria efektywności dynamicznej. In Sprawiedliwość a efektywność (pp. 9-62). Warszawa: Fijorr Publishing.

Stephenson, M. A. (1972). The paradox of value: A suggested interpretation. History of Political Economy, 4(1), 127-139.

Stoiński, A. (2014). Wyzysk w perspektywie sprawiedliwości. Annales. Etyka w Życiu Gospodarczym, 17(3), 31-42.

Wyzysk w prawie cywilnym. (2012). openlaw.pl. http://www.openlaw.com.pl/wikka.php? wakka=Wyzysk

Ziembiński, Z. (1996). Sprawiedliwość społeczna jako pojęcie prawne. Warszawa: Wydawnictwo Sejmowe. 